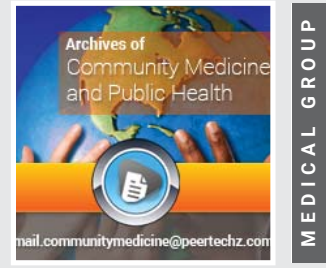

\title{
Pandemics, Public Health and Social Science
}

\section{Ronnie Moore*}

School of Medicine and Medical Sciences, University College Dublin, Dublin, Ireland
Received: 07 January, 2021

Accepted: 18 January, 2021

Published: 20 January, 2021

*Corresponding authors: Ronnie Moore, School of Medicine and Medical Sciences, University College Dublin, Dublin, Ireland, E-mail: ronnie.g.moore@ucd.ie

https://www.peertechz.com
The PREPARE ${ }^{1}$ research consortium is a European Union (EU) funded five-year (plus) investigation (additional funding and aims were added), set up to assess public health and clinical preparedness in the event of an Infectious Disease (ID) pandemic. The project, initiated in 2014 represents an international, multidisciplinary investigation conducted by a range of research clinicians and social scientists, aiming (as a first phase) to identify key structural, behavioural and cultural barriers to the rapid implementation of large multisite clinical studies in Europe (Work package 1, see EARL Reports $)^{2,3}$. This was a complex investigation and included a number of quantitative and qualitative research approaches and strategies. These included, mining various secondary data and official document. In addition, the investigation conducted detailed literature searches on clinical trial authorisation and ethical approval processes in each Member State (MS) of the European union [with some additional countries]; Country mapping of respective country ethics processes, recording Standard Operating Procedures (SOPs), legal, regulations, and ethical and official guidelines; Developing procedures for tracking ethical approval in real-time in various MS; It established a raft of appropriate research strategies, including social surveys, various types of depth interviews, including telephone interviews, and focus groups. These included a range of face-to-face and telephone interviews with relevant key informants (ie, high profile professional stakeholders, Public Health Officials and front-line medical researchers, at different levels) in key member states. The investigation

${ }^{1}$ https://www.prepare-europe.eu/About-us/Workpackages / Workpackage-1

${ }^{2}$ https://www.prepare-europe.eu/Portals/0/Documents/LibraryDocs/ Ethics, $\% 20$ administrative, $\% 20$ regulatory $\% 20$ and $\% 20$ logistic $\% 20$ bottlenecks $\% 20$ and $\% 20$ solutions $\% 20$ for $\% 20$ pandemic-relevant $\% 20$ clinical\%20research\%20in\%20Europe. pdf?timestamp $=1543322479291$

${ }^{3}$ https://ec.europa.eu/research/infocentre/article_en.cfm?artid=52026 therefore sought multiple triangulations via the use of multiple data gathering techniques and data sources within and between quantitative and qualitative methodologies. The detail is published elsewhere (PREPARE EARL Reports 2015 and 2016 and in various associated publications, some listed here).

The context of this project was bound by a growing concern that a serious pandemic was an eminent threat $[1,2]$. This was based on latest information on risk likelihood, as well as observed historical episodes. Increased frequency of threats added to this giving cause for concern in recent years because of rapid sociological and environmental changes, e.g., technology, livestock management and food production, transport, migration, and changes in climatic conditions. The links between globalisation and pandemics are therefore underscored, 'Pandemics are thus often understood as the unintended 'blowback' - or even as the epidemiological footprint - of intensified globalization' [3] and regarded by some as the Third Epidemiological Transition [4].

The weaknesses of national and, in particular, international public health agencies have been cruelly exposed amid the Covid -19 emergency of 2019-20-21. Medical science has limited control over diseases outbreaks, particularly since many of these are unpredictable in terms of likely threat origin, trajectory and mutation. Known viruses can and do mutate (as we see currently with Covid-19 emergency) potentially making vaccines ineffective. In addition, vaccines themselves, as well as risk perception and public attitudes, may even become part of the problem. In light of the emergence of both known and newly identified viruses there is some cause for concern.

However, a biomedical clinical approach, often at the forefront of this type of research, may simply not be enough in itself to identify, control and manage these types of infections. It is argued here that a three-dimensional approach is needed, to include specialists from various branches of the social sciences. Some have argued that public health emergency systems have over-emphasized the clinical sciences [biomedical, Expert 
Systems], and under emphasized, or completely overlooked the social aspects [lay systems] involved [5,6]. The crucial role of the social sciences in clinical and epidemiological research has been underscored by Glasse and Lindenbaum [7,8], for example, in the case of Kuru, and more recently debated by Singer [5]. These approaches can also detail the emic and local interpretations / perceptions, and lifestyle and cultural factors also have an important bearing on disease outbreak, levels of infection, rates of success in research and ultimately in treatment, as well as social organizational issues that may impede effective research. Such Interdisciplinary work now appears to be gaining traction and are understood to be crucially significant in research in the public hearth field. Over the course of the PREPARE investigation the study employed three medical sociologists and one medical anthropologist to assist with a series of investigations into pandemic preparedness

\section{The basic question posed was, Are we prepared?}

In the case of an ID outbreak, there is a coordinated effort from multiple agencies, including public health and clinical fields to effect prevention, containment and management of disease. So there are, usually, (local and national) contingency plans where public health regulations can advise political leaders and assume a level of control. This can range from restraining movement to incarceration. Many international organisations and European countries had such contingency plans in place. (e.g., European Influenza pandemic preparedness plan). However, when PREPARE analysed the nature of these arrangements, we saw that they were patchy and disjointed at the international level. The findings showed that they remained limited in scope and not well defined nor coordinated. Since pandemics recognize no borders, this was (and remains) a considerable international, indeed global, concern. In 2009 the H1NI influenza pandemic spread to 6 continents in three months and infected between $11 \%$ to $21 \%$ of the world's population. The warning from recent Ebola crises indicated that if we treat these public health issues (now with global implications) only at a national or Western-centric level, then effective plans are likely to have very limited effect. Similarly, if we view the problems in terms of national security, then we are perhaps inviting catastrophe. For example, some have outlined the relationship between drug development, production (for example, Tamiflu) and market interests, ie, tied into the national European security discussion [3]. Preparedness is not only about dealing with immediate disease outbreak. It is also about putting in place measures to try to identify diseases, to contain, manage or irradicate outbreaks and it has a socio-legal/political element also involving social control.

Pre Covid-19, it was estimated that within established clinical research practice in Europe (Cancer Research UK), it takes an average 621 days to recruit the first patient after funding is agreed. During the H1N1 pandemic virtually no patients were enrolled into clinical trials, so the optimum treatment of this pandemic remained unknown. This was regarded by many clinicians as a wasted opportunity to conduct research (or to set up procedures and protocols to conduct research).
As of yet it appears that there is currently no agreed and finalized Western European framework for ensuring clinical research is built into epidemic responses and procedures are only now being put in place for rapid research and particularly for the upscaling of international clinical research in times of emergency. This has now been forced amid the recent Covid 19 pandemic. The point is that there is a need for an ongoing preparedness and vigilance plan to include active, coordinated, multi-country, multi-agency efforts, effective and efficient surveillance and rapid ongoing clinical research is regarded as important to develop affordable, safe and effective treatment for clinical management strategies in pandemic situations. These could be proactive rather than periodic reactive outbursts (multiple historical examples pre- and post-1900, illustrate how the world lapsed into a kind of amnesia in the wake of even more serious epidemic outbreaks than Covid-19 and the concern here is that we need to be cognisant of this).

It is however, one thing to call for rapid research but the ability to plan for and conduct such research raises multiple and complex issues. For example, the research process involved in conducting clinical trials is lengthy and cumbersome in a single setting (or health care system). It involves some universally accepted guidelines or standardized operating procedures (SOPs) for example, at a basic level, the application process, ethics committees funding approval, agreed timelines and so on. However, this becomes more complex and problematic when we factor in culture, language and geography, ie in multi-site research. PREPARE have identified these as significant 'blockages' or 'bottlenecks.

\section{What of the role of social science?}

Some have suggested that social scientists (anthropologists) should focus on 'local truths' to help make explicit the local human responses to risks posed by pandemics (for example, why some appear to abide by lockdown advice and others do not; why some see drugs as a threat). Such an emic (bottom up) perspective of behaviour and attitude is crucially significant Moreover, we might also add that within a dominant and over-arching biomedical system, 'local truths' also become important when looking at structural ethical, administrative, regulatory and logistical considerations. In other words, it becomes important to understand real on the ground situations, real Operational Procedures rather than etic (top down) SOPs, in real time, including real structures. In this regard social scientific input has a role to play in looking at the context of structures and / or systems. The utility of social science in medicine is underlined in a recent article in the Lancet [9]. In this sense, the approach is also sympathetic to critically realist strategy, since it also involves looking at underlying structures and assumptions or mechanisms that influence research and practice $[10,11]$. Others have called for an anthropology of epidemics, to provide insight into factors, as well as actors that shape the ongoing production of knowledge about epidemics, How such knowledge is transmitted and how dominant and competing accounts circulate and interact [12].

The PREPARE data has so far indicated multiplex vital problems dogging harmonised research of pandemics. But 
these problems are not insurmountable. They do however, need to be clearly identified first. These range from structural / procedural matters, ie, key ethical and regulatory issues in initiating multi-country clinical studies, to patient participation in clinical trials. For example, the study confirmed that research approval processes and procedures within Europe and even within respective countries were delayed, isolated and fragmented and these were related to a number of structural and social/cultural factors

Other significant issues emerged such as, gaining informed consent and approval (for a specific research purpose). In other words, ethics protocols set up for a specific research purpose with specific individuals or groups is today regarded as the norm in research and specifically in clinical research. But PREPARE found evidence that research consent is interpreted differently in different countries (local truths). Many countries employed specific ethical guidelines (consent and approval for specific research purposes with well-defined individuals or populations within a well specified timeframe). Others employed what might be called broad ethical consent (ie, participants and information were used for other research purposes over and above that for which it was originally intended). Consent, it appeared, was used for further, additional research beyond that explicitly stipulated, for the greater good.

Such considerations led our research team to look more specifically at public involvement and what the public actually thought about giving consent for research during pandemic periods $[13,14]$. Broad consent was largely regarded by some clinical research physicians as pragmatically important, particularly for emergency situations and crucial to harmonising and streamlining research procedures to facilitate rapid research in times of pandemics. The problem is that a dual / multiple consent process raises issues surrounding not only standardisation, but also wider ethical considerations. (ie., big data and the consequences downstream for individuals). The research suggests that there appears to be an issue of balance (individual freedom versus the common good, and the interpretation of this). Within the European context, EU directives introduced in 2014, were also perceived to be adding to bureaucratic blockages of rapid research. Although aspects of how these are defined at the local level appears to be open to local or regional interpretation. One suggested way forward is to establish an ethics pre-approval process, (or sleeping ethics protocols - again, this is not without controversy). The point here being that within democratic states, the general public have a right to be informed and can be polled in relation to how to consent. Such a process may also help in developing future research protocols in public health for other issues and in other places $[15,16]$. PREPARE identified that even within a biomedical (scientific) culture, the idea of uniform SOPs is problematic. The consequences are that this has fuelled a serious debate surrounding individual rights and the public good and it links to wider debates surrounding risk, trust, public understanding and communication [17-20].

This short discussion seeks to open up a more general debate into social and clinical research surrounding pandemics and to include the issue of ethics, the respective roles of clinical science, public health and social science in this process.

\section{References}

1. Fineberg HV (2014) Pandemic Preparedness and Response - Lessons from the H1N1 Influenza of 2009. N Engl J Med 370: 1335-1342. Link: https://bit.ly/3ir6w0G

2. McCloskey B, Dare O, Zumla A, Heymann DL (2014) Emerging respiratory tract infections 2. Emerging infectious disease and pandemic potential: status quo and reding risk of global spread. Lancet Infect Dis 14: 1001-110. Link: https://bit.ly/2LMX1wQ

3. Elbe S, Roemer-Mahler A, Long C (2014) Securing circulation pharmaceutically: Antiviral stockpiling and pandemic preparedness in the European Union. Security Dialogue 45: 440-457. Link: https://bit.ly/2XVpCT9

4. Barrett R, Kuzawa CW, McDade T, Armelagos G (1998) Emerging and re emerging infectious diseases: The third epidemiological transition. Annua Review of Anthropology 27: 247-271. Link: https://bit.ly/35YX2EG

5. Singer M (2009) Pathogens Gone Wild? Medical Anthropology and the "Swine Flu" Pandemic. Medical Anthropology: Cross-Cultural Studies in Health and Illness 28: 199-206. Link: https://bit.ly/38XjZtN

6. Atlani-Duault A, Kendall C (2009) Influenza, Anthropology, and Global Uncertainties. Med Anthropol 28: 207-211. Link: https://bit.ly/2L04prN

7. Glasse RM, Lindenbaum S (1980) South Fore kinship. In: Cook E.A., O’Brien D., editors. Blood and semen, kinship systems of highland New Guinea. University of Michigan Press; Michigan, MI 441-462.

8. Glasse RM, Lindenbaum S (1992) Fieldwork in the South Fore: the process of ethnographic enquiry. In Prion diseases of humans and animals (eds $\mathrm{S}$. B. Prusiner, J. Collinge, J. Powell \& B. Anderton), 77-91. London, UK: Ellis Horwood.

9. Janes C, Corbett K, Jones JH, Trostle J (2012) Emerging infectious Diseases: The role of Social Sciences. Lancet 9857: 1884-1886. Link: https://bit.ly/2XWx28y

10. Bhaskar R (1975) A Realist Theory of Science, York: Books.

11. Archer MS, Bhaskar R, Collier A, Lawson T, Norrie A (1998) Critica Realism. Essential Readings. London; New York: Routledge. Link: https://bit.ly/2XTw50q

12. Briggs CL, Nichter M (2009) Biocommunicability and the Biopolitics of Pandemic Threats. Med Anthropol 28: 189-198. Link: https://bit.ly/2LDgYGw

13. Gobat NM, Butler GC, Francis N, Anthierens S, Bastiaens H, et al. (2016) Public attitudes toward research participation during an infectious disease pandemic: a qualitative study across four European countries. Lancet 388 S51. Link: https://bit.ly/3qsw0xk

14. Gobat NM, Gal M, Francis NA, Hood K, Watkins A, et al. (2015) Key stakeholder perceptions about consent to participate in acute illness research: a rapid, systematic review to inform epi/pandemic research preparedness. Trials 16: 591. Link: https://bit.ly/2XQAxxs

15. Gobat NM, Butler GC, Webb S, Francis N, Stanton H, et al. (2018) What members of the public think about taking part in medical research during an influenza pandemic: an international cross-sectional survey across eight OECD countries. Lancet 392: S1. Link: https://bit.ly/35VxHvn

16. Gobat NH, Gal M, Butler CC, Webb SAR, Francis NA, et al. (2017) Talking to the people that really matter about their participation in pandemic clinical research: A qualitative study in four European Countries. Health Expect 21 387-395. Link: https://bit.ly/3nYwcTB 
17. Lloyd-Smith JO, George D, Pepin KM, Pitzer VE, Pulliam JR, et al. (2009) Epidemic dynamics at the human-animal interface. Science 326: 1362-1367. Link: https://bit.ly/3qyDvTE

18. McCloskey B, Dar O, Zumla A, Heymann DL (2014) Emerging infectious diseases and pandemic potential: status quo and reducing risk of global spread. Lancet Infectious Diseases 14: 1001-1010. Link: https://bit.ly/3oU4lj4
19. Moore RG (2014) (Reports I and II) Co PI, lead and (WP1 coordinator) on Research consortium FP7 Structural and Behavoural / Cultural Barriers to the Rapid Implementation of Large Multi-Site Clinical Studies in Europe in response to Severe Infectious Disease outbreaks.

20. Ronnie Moore is a medical anthropologist and PI with the PREPARE research team.

\section{Discover a bigger Impact and Visibility of your article publication with}

\section{Peertechz Publications}

\section{Highlights}

* Signatory publisher of ORCID

* Signatory Publisher of DORA (San Francisco Declaration on Research Assessment)

* Articles archived in worlds' renowned service providers such as Portico, CNKI, AGRIS, TDNet, Base (Bielefeld University Library), CrossRef, Scilit, J-Gate etc.

* Journals indexed in ICMJE, SHERPA/ROMEO, Google Scholar etc.

- OAI-PMH (Open Archives Initiative Protocol for Metadata Harvesting)

* Dedicated Editorial Board for every journal

* Accurate and rapid peer-review process

* Increased citations of published articles through promotions

* Reduced timeline for article publication

Submit your articles and experience a new surge in publication services (https://www.peertechz.com/submission).

Peertechz journals wishes everlasting success in your every endeavours.

Copyright: $\odot 2021$ Moore R. This is an open-access article distributed under the terms of the Creative Commons Attribution License, which permits unrestricted use, distribution, and reproduction in any medium, provided the original author and source are credited. 